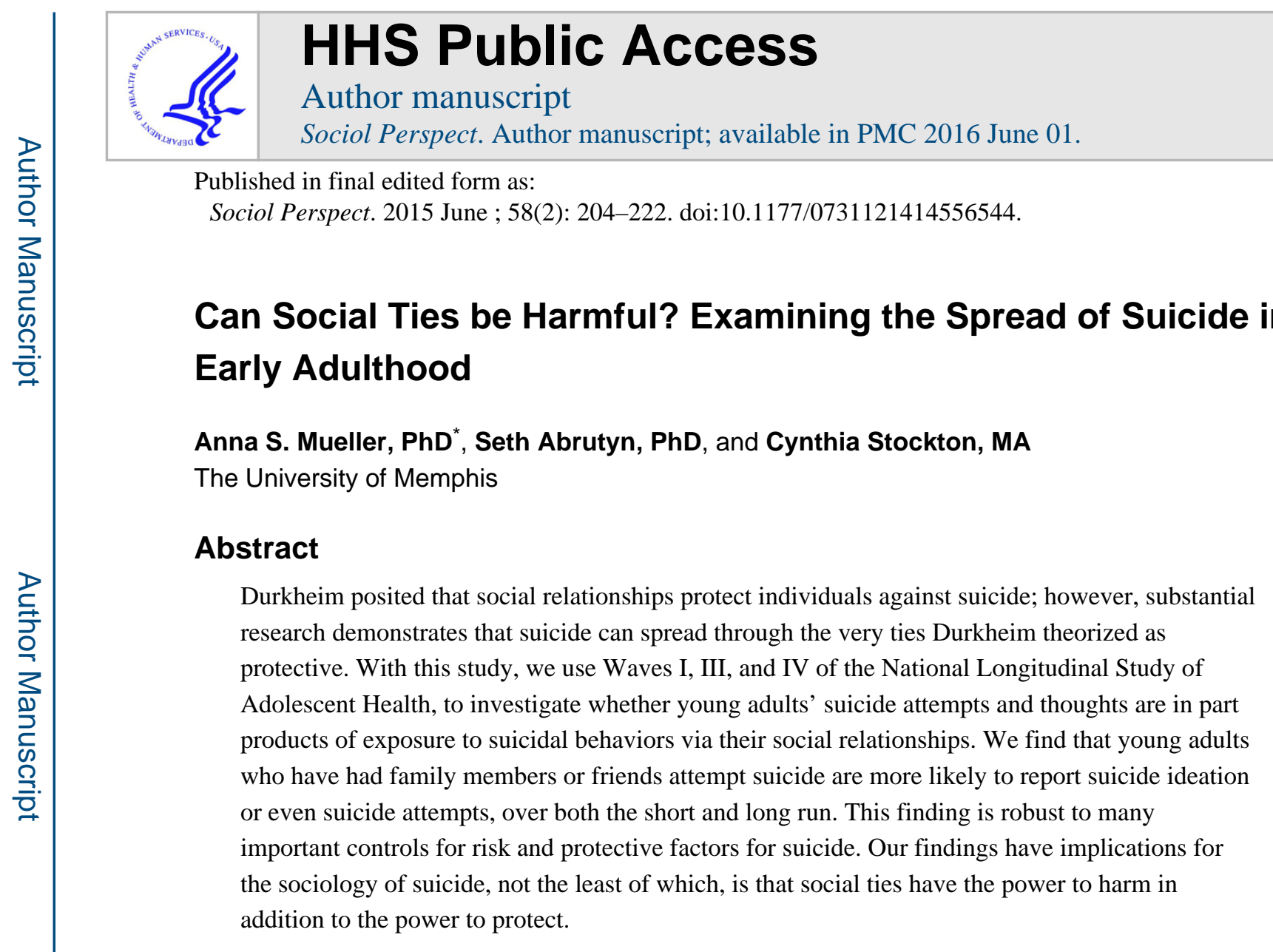

\title{
Keywords
}

suicide ideation; social contagion; suicide suggestion; suicide attempts; role models; Add Health

\begin{abstract}
The sociological study of suicide is often synonymous with Durkheim's (1897 [1951]) classic study, where he argued that social ties can protect individuals against the impulse to self-harm by integrating them into society and providing them with moral regulation. Yet, we also know, particularly from research in social psychology and medical sociology, that social ties have the power to harm individuals' health and wellbeing (Williams 2003; Umberson et al. 2006; Christakis and Fowler 2008; Thomeer, Umberson, and Pudrovska 2013). When significant others expose individuals to unhealthy behaviors, stress, or negative emotions, those relationships can negatively impact people's health and wellbeing (Umberson, Crosnoe, and Reczek 2010). In fact, research has found that exposure to the suicide attempt or the suicide death of a significant other can lead to an increased risk of suicidality and distress in the exposed individual (Bjarnason 1994; Baller and Richardson 2009; Abrutyn and Mueller 2014a). This pattern, sometimes referred to as suicide suggestion, indicates that the role social ties play in promoting or protecting individuals
\end{abstract}

\footnotetext{
*Please address all correspondence to: Anna S. Mueller via phone (901) 678-2612 or anna.mueller@memphis.edu or to Seth Abrutyn via phone (901) 678-3031 or seth.abrutyn@memphis.edu at the Department of Sociology, Clement Hall 231, The University of Memphis, Memphis, TN 38152-3530.

Anna Mueller and Seth Abrutyn contributed equally to this work.

This paper is a revision of a poster presented at the 2012 annual meetings of the Population Association of America.
} 
against suicide is broader than Durkheim's theory allows and that both the positive and negative sides of social ties are worthy of examination.

Suicide suggestion research, with its roots in Gabriel Tarde's (1903) imitation thesis, argues that the natural barriers against self-harm can be worn down and suicide can become a more viable option for coping with emotional distress when individuals experience the suicide attempt or death of someone they deem significant. This research has largely focused on adolescents and has found a consistent association between an adolescent's probability of having serious suicidal thoughts or suicide attempts and an adolescent's exposure to a friend or family member's suicide attempt or death (Farberow et al. 1987; Bjarnason and Thorlindsson 1994; Bearman and Moody 2004; Abrutyn and Mueller 2014a). While this, perhaps, challenges the "conventional" Durkheimian model of suicide, it is not surprising that social ties affect individuals in this way (Abrutyn and Mueller 2014b). Therefore, the task for sociology is to fully elucidate how suicide suggestion works in order to push towards a more nuanced sociological understanding of suicidality.

One major limitation of prior work on suicide suggestion is its focus on adolescents and individuals in bounded social contexts. While it makes sense that adolescents- who are in a more vulnerable life-course stage for suicidality—and individuals in ecologically bounded spaces—like high schools - may be more prone to experiencing suicide suggestion, social relationships play a vital role in the communication of both negative and positive emotions and behaviors across the life course and both inside and out of bounded social spaces (Smith and Christakis 2008; Umberson and Montez 2010). Thus, understanding whether suggestion is a salient part of the suicide process in other stages of the life course and outside of bounded spaces is essential to our sociological understanding of suicide. This study contributes to answering these questions by employing the National Longitudinal Study of Adolescent Health (Add Health) to analyze suicide suggestion via personal role modelslike friends and family members - in early adulthood (when respondents are ages 24-32). Though temporally close in terms of years, key differences exist between young adults and adolescents. Young adulthood reflects a life course stage when self-concept is increasingly more stable and individuals are less prone to conforming to peer influences (Simmons, Rosenberg, and Rosenberg 1973; Demo 1992; Arnett 2003). Further, individuals' lives are generally not focused on one social environment, as is the case with adolescents and schools.

In addition to assessing suicide suggestion in young adulthood, we take advantage of the design of the Add Health data to determine whether suicide suggestion exists above and beyond respondent's suicidality prior to exposure to a role model's suicide attempt and other important risk and protective factors for suicide. Additionally, we use three waves of data to examine whether the suicide attempts of role models are associated with respondent's suicidality over both the short and long run. By addressing these gaps in the current literature, this study deepens our understanding of suicide suggestion, enabling the development of a more robust sociology of suicide. 


\section{THE SPREAD OF SUICIDE}

Famously, Durkheim and his principal rival Gabriel Tarde "debated" whether or not contagion and, perhaps, imitation were sociological processes (Abrutyn and Mueller 2014b). Durkheim's adherence to a theoretical framework that saw social relationships as protective against social pathologies became accepted wisdom and the central theoretical explanation for suicide within sociology (Wray, Colon, and Pescosolido 2011). Today, an orthodox view of Durkheim has become untenable as four decades of mounting evidence indicate that suicides can spread between individuals. Moreover, the idea of social contagion has grown more accepted in various scientific disciplines, as well as pop culture (Gladwell 2000), and researchers have documented the social contagion of various things such as obesity, smoking, and hysterias (cf. Bartholomew and Goode 2000; Christakis and Fowler 2007, 2008, 2009). Additionally, social psychologists have found abundant evidence of the spread of emotions (Hatfield, Cacioppo, Rapson 1994; Collins 2004), particularly negative ones (Howes, Hokanson, and Loewenstein 1985; Larson and Almeida 1999; Summers-Effler 2004). Emotions are crucial mechanisms of social solidarity (Durkheim 1915 [1995]) that motivate individuals to engage in social learning (Stryker 1980) and accept the normative behaviors and attitudes of primary social groups (Turner 2007). In essence, our emotional reactions to the individuals that comprise our social networks are, in part, why these networks matter to our health and wellbeing (Lin 2002; Christakis and Fowler 2009).

\section{Social Contagion and Suicide}

Though outside of the mainstream Durkheimian tradition, anecdotal evidence of the social contagion of suicide has long been reported. For instance, when Goethe published The Sorrows of Young Werther in the late $18^{\text {th }}$ century, several copycat suicides-that is, suicides in which young men dressed like Werther and shot themselves as he did in the novel-were first reported among Goethe's own circle of friends, then in Goethe's home town, and finally across several states within Prussia (Gray 1967). In 1974, David Phillips found a positive association between the publicization of a celebrity's suicide on the front page of a newspaper and suicide rates for local and national audiences. Several studies retested and then extended Phillips' work, finding that (a) political and entertainment celebrities were the most likely to trigger temporary spikes in the suicide rate (Stack 1987), (b) the number of days that the suicide made front page news was positively associated with the duration and intensity of the increase in the suicide rate (Wasserman 1984; Stack 2005), and (c) the "visibility" of the celebrity mattered. For example, Marilyn Monroe's suicide was followed by a 13\% and 10\% increase, respectively, in American and British suicide rates (Phillips 1974). More recently, the suicide death of a high-profile South Korean actress was followed by a 66\% spike in the suicide rate in South Korea (Fu and Chan 2013). Increasingly stringent and conservative statistical tests have continued to support Phillips' initial finding that media publicity can lead to spikes in suicide rates (cf. Stack 2005; Romer, Jamieson, and Jamieson 2006; Gould et al. 2014); less consistent evidence exists, but research has also found an association between televised fictional suicides and increases in audience suicide rates (Schmidtke and Hafner 1988; Stack 2009). 
Research on point clusters - temporally and geographically bounded clusters-provide even greater evidence of how influential role models are in spreading suicidal thoughts and behaviors. Durkheim was aware that penitentiaries, regiments, and monasteries were sites of "epidemic-like" suicide outbreaks, but only recently have there been serious systematic analyses (cf. Haw et al. 2012; Niedzwiedz et al. 2014). When individuals share a collective identity with the decedent, as found in primary groups (e.g., families) and/or physically bounded social contexts (e.g., prisons), the potential for one suicide death to trigger a series of deaths or attempts appears to be heightened. In particular, prisons (Cox and Skeggs 1992), psychiatric wards (Taiminen, Salmenpera, and Lehtinen 1992), Native American reservations (Walls, Chapple, and Johnson 2007), and high schools (Gould, Wallenstein, and Davidson 1989; Davidson 1989) appear to be most vulnerable to outbreaks of suicidal thoughts, suicide attempts and even completions following a community member's suicide death (cf. Gould 2001; Romer et al. 2006). That certain types of networks can facilitate the rapid diffusion of self-harm behaviors is not entirely surprising, particularly if exposure to information about the death is prominent in the community (Gould et al. 2014). However, questions remain about the mechanisms underlying the rapid diffusion of suicidality in communities and their potential link to specific community characteristics.

In an attempt to understand more about these mechanisms, researchers turned to investigating the experiences of individuals with direct exposure to another person's suicide attempt or death. Indeed, not long after Phillips' study, researchers began reporting that adolescents exposed to a friend or family member's attempted or completed suicide were much more likely to report suicidal thoughts (Tishler 1981; Farberow et al. 1987; Bjarnason 1994; Bjarnason and Thorlindsson 1994;Liu 2006) and sometimes attempts (Bearman and Moody 2004). More recently, studies have shown that teenagers who had had no previous suicidal history and who were subsequently exposed to a personal role model's attempted suicide were more likely to develop suicidal thoughts within the next 12 months (Abrutyn and Mueller 2014a). Girls, when exposed to a friend's attempt, were also at risk of attempting suicide within that same time frame. Though this study-and several others (Pescosolido 2006; Baller and Richardson 2009; Abrutyn and Mueller 2014a)—emphasize that social relationships may not always protect against suicidality as Durkheim assumed, several questions remain before we can understand this side of social relationships.

We have identified several important limitations to existing research that we address with this study. First, as we have mentioned, the personal role model research has focused primarily on adolescents. This is at least in part due to practical data limitations - most datasets that contain information on suicide attempts of personal role models employ adolescent samples (for an exception, see Hedström, Liu, Nordvik 2008). It is also likely due to the elevated salience of suicide as a social problem among teenagers. However, teens may be uniquely vulnerable to suicide suggestion because (a) their senses of self are still developing, rendering them vulnerable to peer influences (Giordano 2003), (b) they are less future-oriented than adults and, often, are more concerned with rewards reaped from adolescent society rather than adult society (Steinberg et al. 2009; Crosnoe 2011), and (c) unlike older cohorts, they spend an inordinate amount of their waking lives in a bounded social environment - the high school (Coleman 1961). This latter point is important to note, 
because suicide point clusters - or the appearance of three or more geographically and temporally bound suicides - tend to happen in these types of environments (Niedzwiedz et al. 2014). Not surprisingly, then, some studies have found teens are two to four times more likely to experience a suicide cluster than other age cohorts (Gould et al. 1990). While limited research has examined the impact of a parent's suicide death on young children and finds that children experience an increased risk of suicide after losing their parent to suicide (Niederkrotenthaler et al 2012), the shared genetic and environmental characteristics of parents and children and the developmental vulnerability of early childhood make this a less than ideal test of suicide suggestion outside of adolescence and still leaves us wondering: what about other age cohorts? Is suicide suggestion only a factor for those ages 24 and under?

Young adults - which generally refers to individuals ages 26-35 (Arnett 2000) - make for a compelling age cohort to expand personal role model studies to. First, young adults on average have a more well established identity than adolescents, and their lives are often characterized by higher levels of self-efficacy and by more stable roles than adolescents (McCarthy and Hoge 1982;Demo 1992;Arnett 2003). Thus, the vulnerability that adolescents experience to peer pressure and imitation is likely less prevalent among young adults. At the same time, young adults' increasing independence and sense of self may allow them to form more intimate, stable social relationships (Simmons et al. 1973). This intimacy may provide important protection from self-harm through social integration and moral regulation, but it may also increase the salience of any suicidality that is experienced through a social relationship. Perhaps the most interesting reason to focus on young adults though is that, unlike adolescents, they are no longer focused on one primary bounded social institution. Young adults spend their lives in several spheres of social life with much wider networks than adolescents. Even young adults who are still in college are likely to have substantial networks outside of their institutions of higher education, whether through family, work, religious organizations, or other secondary associations. Hence, the support network should be wider for young adults, and there is less of an opportunity for the effect of the suicidal role model to be amplified through a bounded social context where many peers or similar others are experiencing the same thing. As such, a focus on young adults allows us to leverage existing data sources to examine whether suggestion is dependent on vulnerable life course stages or on bounded social contexts.

Our study permits us to address one final limitation to existing research. Though there are some notable exceptions (e.g., Baller and Richardson 2009; Abrutyn and Mueller 2014a), the vast majority of studies of suggestion use cross-sectional data and, thus, are unable to examine (1) whether pre-existing risk factors for suicide explain the association between respondents and role model's suicidality and (2) how long the harmful effects of exposure to a significant other's suicidality may last. With regard to pre-existing risk factors, the issue research on suicide suggestion must contend with is that respondents are likely to be similar to their role models in terms of both risk and protective factors for suicidality. For example, certain risk factors for suicide (e.g., depression) are also known to shape who individuals befriend (Schaefer, Kornienko, and Fox 2011). Family members, by virtue of both nature and nurture, are also likely to be similar to each other. Thus, the task for suicide suggestion research is to isolate the possible effect of a role model's suicide attempt from these 
potential pre-existing similarities between respondents and role models. To address this limitation, we include a substantial group of sociological and psychological controls for known risk and protective factors for suicide in our models so as to better isolate the role that suggestion plays in suicidality, to the extent possible with survey data.

The second limitation to using cross-section data is that it precludes an examination of the temporality of suggestion. Though not systematically studied, spikes in suicide rates following media coverage of a suicide death seem to last two to four weeks, but can sometimes last longer (Phillips 1974;Stack 1987). Given the social psychological literature on significant others (Stryker 1980;Lawler 2006), we hypothesize that the effects of a personal role model's suicide attempt will last longer than the two to four weeks that are documented in studies of media coverage and suicide rates. Indeed, one study that examined how long the effect lasts for adolescents found that the significant association between the suicide attempt of a friend or family member and a respondent's suicidality lasted at least 12 months and, among girls, was observable even 5 years after the exposure (Abrutyn and Mueller 2014a). With this study, we examine both the immediate and long-term effects a role model's suicide attempt has on young adults ages 24-32.

In sum, with this study, we investigate how suicidality spreads between personal role models in young adulthood to further illuminate understandings of this social mechanism for suicide. We focus on two major gaps in existing literature: (1) we determine whether suicide suggestion is salient to young adults' suicidality; and (2) we use longitudinal data to examine how long the effect of suggestion lasts while controlling for important potentially confounding factors related to suicide. By answering these questions, our study contributes to developing a more robust sociology of suicide.

\section{METHODS}

\section{Data}

This study employs data from Waves I, III, and IV of the National Longitudinal Study of Adolescent Health (Add Health). Add Health contains a nationally-representative sample of adolescents in grades 7-12 in 132 middle and high schools in 80 different communities across the U.S. Add Health is a longitudinal survey that began with an adolescent sample that was followed into young adulthood. The purpose of the study is to understand how social environments-from families to schools to peers-shape adolescent health, behavior, wellbeing, and educational attainment. Add Health uses a complex sampling frame to achieve a nationally representative sample. First, from a list of all schools containing an eleventh grade in the U.S., Add Health selected a nationally-representative sample of schools using a school-based, cluster sampling design, with the sample stratified by region, urbanicity, school type, ethnic composition, and size. Additionally, a feeder school (that contained a $7^{\text {th }}$ grade and sent graduates to the Add Health high school) was chosen for each Add Health high school. From the participating schools, Add Health then conducted the preliminary In-School Survey which collected data from all students in all Add Health schools ( $\mathrm{n}=90,118$ students) in 1994-1995. From that sample, a nationally-representative sub-sample was interviewed at Wave I $(n=20,745)$ shortly after the In-School Survey (in 1994-95). Wave II followed in 1996, and Wave III was collected in 2001-2002, when 
respondents were aged 18-26. Most recently, and germane to our analysis, Wave IV occurred in 2008 and 2009 when respondents were ages 24-32. Approximately $80 \%$ of the original Wave I sample was re-interviewed at Wave IV and 14,800 youth participated in Wave I, III and IV. While each wave of data collection included many of the same items as previous waves of Add Health, additional sections pertinent to young adults such as family formation and work experiences were also added to Wave IV. Additional information about Add Health can be found in Harris et al. (2009).

\section{Sample Selection}

We use several sample selection filters to produce analytic samples that allow us to assess suicide suggestion in young adulthood. First, we select respondents with valid sample weights $(\mathrm{N}=14,800)^{1}$ so that we can properly account for the complex sampling frame of the Add Health data. 901 individuals have missing sample weights because they were missing Wave I sample weights (usually because they were part of an oversampled population and not eligible for Add Health's grand sample). We include Wave I data in our analyses so that we have a measure of respondent's suicidality prior to exposure to the suicide attempt of a role model. This also allows us to account for potential unmeasured factors by including a lagged version of our dependent variables in all models (Shadish, Campbell, and Cook 2002). Finally, we exclude respondents who are missing on any key independent variables. Our final analytic sample size is 10,852. Because these filters have the potential to bias our findings, we explored alternate ways of handling missing data. Specifically, in alternate analyses available from the authors by request, missing values on all independent variables (except the key independent variables, Role Model Suicide Attempt at Wave III and Wave IV) were imputed through multiple imputation by the MICE system of chained equations in Stata/SE 13.1 (Royston 2009). Because handling missing data with multiple imputation did not result in findings that were substantively different from our findings using list-wise deletion, we have opted to handle missing data via list-wise deletion. Table 1 presents weighted descriptive statistics for our analytic samples.

\section{Measures}

Dependent Variables-With this study, we examine two aspects of suicidality at Wave IV: suicide ideation and suicide attempts. Suicidal Ideation is based on respondents' answers to the question: "During the past 12 months, did you ever seriously think about committing suicide?" Young adults who answered "yes" were coded as 1 on a dichotomous outcome indicating suicidal ideation. Respondents who reported having suicidal thoughts were then asked, "During the past 12 months, how many times did you actually attempt suicide?" Answers ranged from 0 ( 0 times) to 4 (6 or more times). We use respondents' answers to this question to measure Suicide Attempts at Wave IV. Respondents' answers were recoded into a dichotomous variable where 1 indicates a report of at least one suicide attempt in the past 12 months and 0 indicates no attempts. Individuals who reported no suicidal thoughts were coded as 0 on Suicide Attempts. These two survey items were asked at Wave I as well; thus, all models include respondents' Suicide Ideation (without an attempt) and Suicide

\footnotetext{
${ }^{1}$ We use the longitudinal sample weight GSWGT4_2 because we do not use data from Wave II of Add Health.
} 
Attempts at Wave I as an important controls for unmeasured confounds (Shadish et al. 2002).

Independent Variables-Our first key independent variable is Role Model Suicide Attempt at Wave IV. At Wave IV, respondents were asked only one question regarding suicide attempts by role models: "During the past 12 months, have any of your family or friends tried to kill themselves?" Responses were coded as " 1 " for yes and " 0 " for no on a variable representing exposure to role models suicidality (Role Model Suicide Attempt Wave $I V)$. Our second key independent variable is Role Model Suicide Attempt Wave III and is based on respondents' answers to two questions: "Have any of your friends tried to kill themselves during the past 12 months?" and "Have any of your family tried to kill themselves during the past 12 months?" Young adults who responded "yes" to either question are coded as 1 on a dichotomous variable. We collapsed these two questions into one measure of role model suicide attempt to be parsimonious with how the question was asked at Wave IV and to provide us with enough statistical power to analyze suicide attempts as a dependent variable.

Control Variables-Our models also control for risk and protective factors for suicide identified by prior research. First we control psychological risk factors from adolescence and young adulthood. In addition to respondent's suicidality at Wave I, we include whether respondents experienced emotional, physical or sexual abuse while growing up. These forms of abuse are known to increase respondents' vulnerability to suicidality (Joiner 2005). To measure abuse, we used survey items from Wave IV. Respondents were asked how often before their $18^{\text {th }}$ birthday a parent or other adult caregiver (1) said things that made the respondent feel hurt or feel that they were not wanted or loved, (2) hit them with a fist, kicked them, or threw them down on the floor, into a wall, or down stairs, and (3) touched them in a sexual way, forced them to touch him or her in a sexual way, or forced them to have sexual relations. Because the modal value was "never" on all three survey items, we created three separate dichotomous indicators of each type of abuse. A "1" indicates respondents who experienced emotional, physical or sexual abuse and " 0 " represents respondents who did not. In addition to the reports of childhood abuse, we control for psychological risk factors for suicide in young adulthood. First, all models also control for whether the respondent reports being diagnosed with depression by a doctor $(\mathrm{Y} / \mathrm{N})$. Second, because recent research suggests that sleep disturbances increase the risk of suicidality (Wojnar et al. 2009; Wong and Brower 2012), we include an indicator of whether the respondent is currently experiencing sleep problems, such as an inability to fall asleep, stay asleep, or significant breathing difficulties while sleeping. Finally, there is a welldocumented association between alcohol abuse and suicidality (Hufford 2001; Spirito and Esposito-Smythers 2006); therefore, we created a dichotomous variable that identifies respondents who meet the DSM-4 criteria for alcohol abuse or dependence (based on Add Health's constructed variable C4VAR023) and report current alcohol use.

Because social integration can protect individuals from suicide (Gibbs 2000), we include a series of measures capturing how socially integrated respondents are. Our first measure of social integration is whether respondents have children. This variable is a dichotomous 
indicator ( $1=$ has children, $0=$ does not have children) and is taken from the household roster data. Relationship status is constructed using Add Health's relationship history data. From this data we identify respondent's current relationship and create four mutually-exclusive statuses: married (0/1), divorced (0/1), cohabiting (0/1), and single (which includes widowed individuals and individuals who are dating) as the reference group. Divorced individuals are identified if they are currently single or dating and they report a past relationship that was a marriage. If individuals are remarried or cohabiting after they are divorced, they are coded as " 0 " on divorced. Respondents also report how happy they are with their current romantic partner and how close they feel to that partner. There are three possible response categories for happiness with current romantic partner: very happy, somewhat happy, and not happy. We created two dichotomous indicators - one for very happy (yes/no) and one for not happy (yes/no) - and use "somewhat happy" as the reference group. Respondents are also asked on a scale of 1 to 7 how close they felt to their partner, with higher values indicating a closer relationship. Individuals who are not in romantic relationships receive a 0 on both of these measures.

Families of origin can also be important sources of social integration; thus, we control two aspects of respondent's relationships with their parents. First, respondents were asked how close they feel to their mother and father figures. The maximum value between closeness to mother and closeness to father was taken and used to create a measure of closeness to parents. Other permutations of this variable were explored, as well as separate scales for fathers and mothers; all resulted in substantively similar findings. Second, we created a dichotomous indicator for respondents whose family of origin was intact at Wave I (in other words, respondents with parents who were married to each other). Our final measure of social integration captures how involved respondents are with religious organizations, a known protective factor for suicide (Pescosolido and Georgianna 1989). At Wave IV respondents were asked how often they attended religious services. Responses ranged from "never" to "once a week, or more". Items were reverse coded so that a higher value on this measure indicates more frequent religious attendance.

In addition to social integration, our models include controls for demographic factors. These include respondent's age, biological sex, race, sexual orientation, parents' education level, respondent's education level, socioeconomic status, employment status, and military status. Race is coded as five of dichotomous variables: Latino, Black, Asian and Other, with White as the reference category. Sexual orientation was measured by respondents' identification of their sexual identity ranging from $100 \%$ homosexual to $100 \%$ heterosexual (with not attracted to males or females as an option). Those who reported being "bisexual," "mostly homosexual (gay), but somewhat attracted to people of the opposite sex," and " $100 \%$ homosexual (gay)" were coded has 1 . Heterosexual, asexual and mostly heterosexual respondents were coded as 0 . Parents' education was taken from the parent questionnaire (at Wave I) and the maximum value was taken in the case of two parents. If the information was missing from the parent questionnaire, the students' report of their parents' education level was used. Parents' education was coded as (0) for never went to school; (1) less than high school graduation; (2) high school diploma or equivalent; (3) some college, but did not graduate; (4) graduated from a college or university; and (5) professional training beyond a 4 -year college or university. Four dichotomous indicators of respondents' highest degree 
attained also are included in all models. The indicators include whether respondents dropped out of high school (1/0); have a high school diploma or equivalency; have completed some college but do not have a bachelor's degree (0/1); and whether they have a bachelor's or graduate degree (which serves as our reference group) (0/1). Models also include respondents' self-reported socioeconomic status. Respondents were asked on a scale of 1 to 10 to identify their own status in terms of both education and income relative to other Americans. In addition to SES and education, we include a flag for respondents who are currently unemployed. Finally, because serving in the military during times of war is a risk factor for suicide (Cesur, Sabia, and Tekin 2013), we control for whether respondents have served or are serving in the military.

\section{Analytic Plan}

To investigate our research questions, we estimate a series of nested logistic regression models controlling for respondents' history of suicidal thoughts at Wave I. As a first step, we estimate the relationships between a role model's suicide attempt (at Wave III or IV) and the likelihood of suicide ideation and attempt (at Wave IV) controlling only for adolescent psychological risk factors to determine whether suicide suggestion is part of the suicidal process of young adults above and beyond respondents' psychological histories. Next, we add our set of demographic controls and measures of social integration to the model to determine how robust the impact of suicide suggestion is to potentially confounding risk and protective factors. Finally, we add measures of psychological risk factors in young adulthood. A suicidal role model may increase other aspects of psychological distress in young adulthood (such as depression or sleep problems), and it is important to determine whether suggestion exists above and beyond these important controls.

All models are estimated using the SAS SurveyLogistic Procedure (An 2002) to account for the complex sampling frame of the Add Health data. Additionally, all models include normalized sample weights to compensate for Add Health's sampling design and sample attrition. These weights render our analyses more representative of the U.S. population than unweighted analyses that fail to correct for Add Health's oversampled populations.

\section{RESULTS}

\section{Suicide Suggestion in Young Adulthood}

To begin our examination of suicide suggestion in young adulthood, we start by analyzing the relationship between experiencing a role model's suicide attempt at Wave IV and respondent's suicidality at Wave IV. Our first model, presented in Table 2, estimates the effect of role model suicide attempts net of adolescent psychological risk factors and finds that, on average, there is a strong and significant association between having a role model attempt suicide and respondents reporting suicidal thoughts ( $\mathrm{OR}=2.186, \mathrm{p}<.0001)$. In Model 2 , we add important demographic and social controls to the model to see if these factors explain the significant association between role models and respondents' suicide ideation. In Model 2, respondents' odds of reporting suicide ideation remain significantly higher if they also report having a friend or family member attempt suicide in the past 12 months $(\mathrm{OR}=1.990, \mathrm{p}<.0001)$, net of these additional controls. Model 3, our saturated model, adds 
psychological risk factors in young adulthood, such as diagnosed depression, alcohol abuse, and troubled sleep, to the model. Net of all controls, on average, respondents who report having a role model attempt suicide are 1.878 times more likely to report suicidal thoughts $(\mathrm{p}=.0007)$.

Models 4, 5, and 6 in Table 2 analyze the effect of role models on respondent's likelihood of attempting suicide in the past 12 months. The pattern of our findings is similar to our findings regarding respondents' suicide ideation (Models 1-3). Though our measures of demographic characteristics and social integration (Model 5) and young adult psychological risk factors (Model 6) mediate some of the relationship between role model's suicide attempts and young adults' likelihood of reporting a suicide attempt, respondents who have had a friend or family member attempt suicide in the past 12 months are significantly more likely to report suicide attempts at Wave IV. Specifically, net of all other variables, our saturated model (Model 6) shows that on average, respondents who report that a friend or family member attempted suicide are 3.526 times more likely to also report that they have attempted suicide in the last 12 months ( $\mathrm{p}=.003)$.

\section{The Longitudinal Effect of a Role Model's Suicide Attempt}

Next we turn our attention to examining whether the significant association between role models and respondents' suicidality lasts over time (Table 3). To do this, we examine whether respondents' who report that a family member or friend attempted suicide at Wave III are more likely to report suicide ideation and suicide attempts at Wave IV, net of our control variables. Table 3 presents these results. We begin again with our most basic model that only controls adolescent psychological risk factors, including our prior measure of our dependent variable (suicide ideation and attempts at Wave I). Model 1 shows that, net of respondents' histories of suicidality, respondents who had a role model attempt suicide (at WIII) are 1.504 times more likely to report suicidal thoughts at Wave IV, which is approximately 6 years later $(\mathrm{p}=.006)$. Model 2 adds our controls for social integration and demographic characteristics and reveals that this association remains significant net of these controls: on average, young adults who report that a friend or family member attempted suicide at Wave III are 1.370 times more likely to report suicidal thoughts at Wave IV, net of all other factors ( $\mathrm{p}=0.038$ ). Model 3 adds psychological risk factors for suicide at Wave IV - namely diagnosed depression, alcohol abuse, and sleep problems - and these factors explain away the significant effect of role model's suicide attempt on young adults' suicidal thoughts 6 years after the role model's attempt. This may suggest that one way that suicide suggestion operates over the long run is by increasing psychological distress and its comorbidities (such as substance abuse and sleep problems) that in turn have their own significant and independent association with a heightened risk for suicidality.

Next we investigate the effect of role model's suicide attempts at Wave III on young adults' likelihood of reporting a suicide attempt at Wave IV (Models 4-6 in Table 3). The pattern remains almost identical to the pattern observed for suicide ideation; our controls for respondents' psychological wellbeing, social integration, and demographic factors partially explain why suicide suggestion is observed. The major difference is that the significant effect of role model's suicide attempt on respondent's reports of having attempted suicide in 
the last 12 months remains significant in our saturated model (Model 6). Specifically, net of psychological risk factors in young adulthood and adolescence, measures of social integration, and demographic characteristics, young adults who report a role model attempted suicide at Wave III are, on average, 2.189 times more likely to report a suicide attempt approximately 6 years after the role model's attempt than their otherwise similar peers who have not had a role model attempt suicide $(\mathrm{p}=.049)$.

Finally, it is worth mentioning the strong and significant relationship between respondents' history of suicidality at Wave I and their suicidal thoughts and suicide attempts at Wave IV. Attempting suicide in adolescence significantly and substantially increases the odds that a respondent will report suicide ideation and even a suicide attempt in young adulthood. This is one of the most robust and consistent predictors of suicidality in our models. The only other consistently significant risk factors are being diagnosed with depression at Wave IV, experiencing emotional abuse as a child, and having a role model attempt suicide.

Taken as a whole, our findings indicate that suicide suggestion may be a significant risk factor for suicide in young adulthood and that suggestion does not require bounded social contexts to be salient.

\section{DISCUSSION}

Sociological research on suicide has predominantly followed the Durkheimian tradition, emphasizing how social ties protect individuals from suicide through social integration and moral regulation. This emphasis is at odds with existing research on the negative impact social ties can have on individuals' health, wellbeing, and even likelihood of reporting suicidal thoughts or attempts. With this study, we add to the growing body of literature that demonstrates that close social relationships can serve not just as sources of support, but also as conduits for the spread of suicidal behaviors. We find that when a close friend or family member attempts suicide, young adults are more likely to report suicidal thoughts and even attempts, net of important psychological and sociological controls, such as that person's history of suicidality prior to the attempt of their friend or family member. We also find that the suicide attempt of a friend or family member can play an essential and long-term role in individual's suicidality. Even six years later, a significant association is observed between a role model's suicide attempt and respondent's suicide ideation and attempts, though respondent's psychological distress in young adulthood mediates the relationship to some extent. Our findings provide further evidence that the sociology of suicide must evolve and consider both the protective and harmful effects that social relations can have on an individual's suicidality.

Our study has three primary implications for advancing the sociological understanding of suicide generally and the sociological research on suicide suggestion specifically. First, prior research on suicide suggestion has focused almost exclusively on the adolescent population. Because adolescents have several characteristics that may render them particularly vulnerable to suicide suggestion as a mechanism, we cannot extrapolate findings from studies of adolescents to stages of the life course, and thus our understanding of suicide suggestion has been limited. By examining young adults, who, while temporally close to 
adolescents in terms of years, do not have the same inherent vulnerabilities to peer influence, we can be more confident that suicide suggestion is an important sociological mechanism in the suicide process.

Second, prior research on the social contagion of suicide has primarily examined populations whose lives are focused within bounded social spaces, such as high schools, psychiatric wards, or Native American reservations. While it makes sense that bounded social spaces may increase the salience of suicide suggestion or may amplify social contagion processes, it is important to determine whether suggestion is dependent upon a bounded social space. Young adults' lives are not constrained to one social environment as is often the case with adolescents and high schools. Thus, by examining suggestion in young adulthood, we are able to provide evidence that the contagion of suicide is likely not dependent on bounded social contexts as long as a direct relationship between an individual and the suicidal role model exists. Put differently, when individuals are exposed to the suicide attempt of someone they care about, the exposure is significantly associated with their mental health and likelihood of reporting suicidality.

Third, using longitudinal data that includes respondent's histories of suicidality prior to exposure to the suicide attempt of a role model and their suicidality after exposure, allows us to test whether suggestion is (1) merely a product of pre-existing risk factors for suicidality and (2) how long the significant association between role models' and respondents' suicidality lasts. We find that, in young adulthood, respondents who had a role model attempt suicide are significantly more likely to report attempting suicide over both the short and long run, compared to their otherwise similar peers; even once we take into account important psychological factors (both in adolescence and young adulthood) and measures of risk and protective factors for suicidality. Furthermore, young adults who report that a friend or family member attempted suicide are more likely to report suicide ideation, though over the long run, the relationship between a role model's suicide attempt and a young adult's suicidal thoughts appears to be mediated by psychological distress. Given the potential longterm impact the attempt of a role model has on young adults and how robust this association is to potential mediators, we can be more confident that suicide suggestion is a serious and important part of the suicide process.

Despite these important contributions to our understanding of suicide suggestion, there are some limitations to this study that are worth noting. First, we focus our analysis of young adults' suicidality on suicidal thoughts and attempts and not suicide deaths due to the limited number of respondents who have died by intentional self-harm in the Add Health data.

According to Add Health, only 22 respondents have died due to intentional self-harm, which is insufficient for a multivariate statistical analysis such as this one (Add Health 2014). Similarly, we are not able to analyze role models who died by suicide and role models who survived a suicide attempt separately because of sample size limitations. In our data, approximately one third of role models' completed suicide and two thirds attempted but did not complete suicide at both Waves III and IV. Considering the intense negative emotions that individuals who have lost a loved one to suicide report (Fine 2000; Linn-Gust and Cerel 2011), future research should endeavor to collect data that allows us to examine this potentially important difference. Also due to data limitations, we were unable to distinguish 
between friends and family-based role models at Wave IV due to how Add Health asked the survey item. To be consistent, we constructed our Wave III measure of role model suicide attempts to mirror the Wave IV survey item; however, we acknowledge that friends and family may play distinct roles in the suicide suggestion process and future research should investigate how individuals' relationships to the role model condition the experience of suicide suggestion. Additionally, it was beyond the scope of this study to fully investigate what role shared context may play in suicide suggestion. It may be that role models and respondents share environments or experiences that contribute to both the suicide attempt of role models' and the suicidality of respondents. This is an important direction for future research. Finally, while we did our best to account for respondents' vulnerability to suicide prior to exposure to the suicide attempt of a friend or family member, we must acknowledge that survey data is never going to be able to fully account for social selection. Hence, while our study represents an important step forward by using longitudinal data and extensive controls for other risk and protective factors, we still cannot conclude that the suicide attempt or death of a role model causes an increased risk of suicidality among young adults.

As a final point, it is worth mentioning that there are important gender and race and ethnic differences in suicidality that we were unable to examine with our data (Stack 2000; BacaGarcia et al. 2008). Suicide ideation is rare in young adulthood, and suicide attempts are rarer still. Likewise, only approximately $6 \%$ of young adults report experiencing the suicide attempt of a role model. Given our desire to analyze the intersection of these two relatively rare events in order to understand important issues relating to suicide suggestion, we had to neglect potential gender and race or ethnic differences in the experience of a role model's suicide attempt. This omission should be addressed by future research. We suggest that future research (1) use qualitative methods to analyze gender and race/ethnic differences in the experience of role models' suicide attempts or deaths or (2) focus on other measures of mental health and wellbeing, such as emotional distress, alcohol abuse, or sleep problems, that will still shed light on important aspects of the experience of a role model's suicide attempt or death.

\section{CONCLUSION}

Despite its divergence from the dominant sociological Durkheimian model of suicide, the propensity for suicides to spread via social ties is widely recognized by sociologists, public health researchers, and suicide prevention specialists. Regardless of life course stage or the presence of a bounded social context, experiencing the suicide death or attempt of a significant other can greatly increase the likelihood that a person reports serious suicidal thoughts or even suicide attempts. For young adults, similar to adolescents, social ties have the potential to both protect and place them at risk of suicide. Knowing that two or more individuals are closely integrated does not reveal important information about the norms or qualities embedded within those social ties. While sociology's main contribution to the scientific study of suicide undoubtedly has evolved from Durkheim's classic study, sociology has the tools to broaden our contribution to suicidology and help prevent one of the leading causes of death in the early life course. Thus, we argue that the next important task for the sociology of suicide is to integrate Durkheim's important insights about the power of socially integrative ties with insights from social psychology, sociology of 
emotions, and social network theories in order to create a more robust and comprehensive understanding of how social forces condition suicidality.

\section{Acknowledgments}

Anna Mueller and Seth Abrutyn contributed equally to this work. The authors would like to thank Dara Shifrer and three anonymous reviewers for their insightful comments and suggestions.

Funding Statement:

This research uses data from Add Health, a program project directed by Kathleen Mullan Harris and designed by J. Richard Udry, Peter S. Bearman, and Kathleen Mullan Harris at the University of North Carolina at Chapel Hill, and funded by grant P01-HD31921 from the Eunice Kennedy Shriver National Institute of Child Health and Human Development, with cooperative funding from 23 other federal agencies and foundations. Special acknowledgment is due Ronald R. Rindfuss and Barbara Entwisle for assistance in the original design. Information on how to obtain the Add Health data files is available on the Add Health website (http://www.cpc.unc.edu/addhealth). No direct support was received from grant P01-HD31921 for this analysis. Opinions reflect those of the authors and do not necessarily reflect those of the granting agencies.

\section{References}

Abrutyn, Seth; Mueller, Anna S. Are Suicidal Behaviors Contagious? Using Longitudinal Data to Examine Suicide Suggestion. American Sociological Review. 2014a; 79(2):211-27. [PubMed: 26069341]

Abrutyn, Seth; Mueller, Anna S. Reconsidering Durkheim's Assessment of Tarde: Formalizing a Tardian Theory of Imitation, Contagion, and Suicide Suggestion. Sociological Forum. 2014b; 29(3)

Abrutyn, Seth; Mueller, Anna S. The Socioemotional Foundations of Suicide: A Microsociological View of Durkheim's Suicide. Sociological Theory. 2014c (Forthcoming).

Add Health. Add Health Wave IV Documentation: Cause of Death. Retrieved May 6, 2014.http:// www.cpc.unc.edu/projects/addhealth/data/restricteduse/datasets

An, Anthony. Performing Logistic Regression on Survey Data with the New SURVEYLOGISTIC Procedure. Paper 258-27. Proceedings of the 27th Annual SAS Users Group International Conference (SUGI 27); Orlando, FL. April 14-17 2002; 2002. p. 1-9.

Arnett, Jeffrey Jensen. Emerging Adulthood: A Theory of Development from the Late Teens Through the Twenties. American Psychologist. 2000; 55(5):469-80. [PubMed: 10842426]

Arnett, Jeffrey Jensen. Conceptions of the Transition to Adulthood Among Emerging Adults in American Ethnic Groups. New Directions for Child and Adolescent Development. 2003; 100:6375. [PubMed: 12955983]

Baca-Garcia, Enrique; Mercedes Perez-Rodriguez, M.; John Mann, J.; Oquendo, Maria A. Suicidal Behavior in Young Women. Psychiatric Clinics of North America. 2008; 31:317-31. [PubMed: 18439451]

Baller, Robert D.; Richardson, Kelly K. Social Integration, Imitation, and the Geographic Patterning of Suicide. American Sociological Review. 2002; 67(6):873-88.

Baller, Robert D.; Richardson, Kelly K. The "Dark Side" of the Strength of Weak Ties: The Diffusion of Suicidal Thoughts. Journal of Health and Social Behavior. 2009; 50:261-76. [PubMed: 19711805]

Bartholomew, Robert E.; Goode, Erich. Mass Delusions and Hysterias: Highlights from the Past Millennium. Skeptical Inquirer. 2000; 24:20-8.

Bearman, Peter S. The Social Structure of Suicide. Sociological Forum. 1991; 6(3):501-24.

Bearman, Peter S.; Moody, James. Suicide and Friendships Among American Adolescents. American Journal of Public Health. 2004; 94(1):89-95. [PubMed: 14713704]

Bjarnason, Thoroddur. The Influence of Social Support, Suggestion and Depression on Suicidal Behavior among Icelandic Youth. Acta Sociologica. 1994; 37(2):195-206. 
Bjarnason, Thoroddur; Thorlindsson, Thorolfur. Manifest Predictors of Past Suicide Attempts in a Population of Icelandic Adolescents. Suicide and Life Threatening Behavior. 1994; 24:350-58. [PubMed: 7740593]

Cesur, Resul; Sabia, Joseph J.; Tekin, Erdal. The Psychological Costs of War: Military Combat and Mental Health. Journal of Health Economics. 2013; 32(1):51-64. [PubMed: 23220456]

Centers for Disease Control and Prevention. Suicidal Thoughts and Behaviors Among Adults Aged $\geq 18$ Years - United States, 2008-2009. MMWR Survellience Summaries. 2011; 60(SS-13) Retrieved June 3, 2013 (http://www.cdc.gov/mmwr/pdf/ss/ss6013.pdf).

Centers for Disease Control and Prevention. Suicide - Facts at a Glance. Atlanta, GA: Centers for Disease Control and Prevention; 2012. Retrieved June 20 ${ }^{\text {th }}, 2013$ (http://www.cdc.gov/ violenceprevention/pdf/suicide_datasheet_2012-a.pdf)

Centers for Disease Control and Prevention. Youth Risk Behavior Surveillance - United States, 2011. MMWR. 2012; 61(SS-4):1-168. Retrieved June 3, 2013 (http://www.cdc.gov/mmwr/pdf/ss/ ss6104.pdf).

Christakis, Nicholas A.; Fowler, James H. The Spread of Obesity in a Large Social Network Over 32 Years. The New England Journal of Medicine. 2007; 357:370-9. [PubMed: 17652652]

Christakis, Nicholas A.; Fowler, James H. The Collective Dynamics of Smoking in a Large Social Network. New England Journal of Medicine. 2008; 358(21):2249-2258. [PubMed: 18499567]

Christakis, Nicholas A.; Fowler, James H. Connected: How your Friends' Friends' Friends Affect Everything You Feel, Think and Do. New York: Back Bay Books; 2009.

Coleman, James Samuel. The Adolescent Society: the Social Life of the Teenager and its Impact on Education. Free Press of Glencoe; 1961.

Collins, Randall. Interaction Ritual Chains. Princeton: Princeton University Press; 2004.

Cox, Brian; Skegg, Keren. Contagious Suicide in Prisons and Police Cells. Journal of Epidemiology and Community Health. 1993; 47(1):69-72. [PubMed: 8436899]

Crosnoe, Robert. Friendships in Childhood and Adolescence: The Life Course and New Directions. Social Psychology Quarterly. 2000; 63:377-91.

Crosnoe, Robert. Fitting in, Standing Out: Navigating the Social Challenges of High School to Get an Education. Cambridge University Press; 2011.

Davidson, Lucy. An Epidemiologic Study of Risk Factors in Two Teenage Suicide Clusters. Journal for the American Medical Association. 1989; 262(19):2687-92.

Davis, Mark H. Empathy. In: Stets, JE.; Turner, JH., editors. Handbook of the Sociology of Emotions. New York: Springer; 2006. p. 443-66.

Demo, David H. The Self-Concept Over Time: Research Issues and Directions. American Sociological Review. 1992; 18:303-26.

Durkheim, Emile. Suicide: A Study in Sociology. Glencoe, Ill: Free Press; 1897,1951.

Durkheim, Emile. The Elementary Forms of Religious Life. New York: Free Press; 1915,1995.

Farberow, Norman L.; Galagher, Dolores E.; Gilewsky, Michael K.; Thompson, LW. An Examination of the Early Impact of Bereavement on Psychological Distress in Survivors of Suicide. Gerentologist. 1987; 27:592-98.

Fine, Carla. No Time to Say Goodbye: Surviving the Suicide of a Loved One. New York: Broadway Books; 2000.

$\mathrm{Fu}$, King-wa; Chan, CH. A Study of the Impact of Thirteen Celebrity Suicides on Subsequent Rates in South Korea from 2005 to 2009. PLoS ONE. 2013; 8(1):e53870.10.1371/journal.pone.0053870 [PubMed: 23342026]

Gibbs, Jack. Status Integration and Suicide: Occupational, Marital, or Both? Social Forces. 2000; 79(2):363-84.

Giordano, Peggy C. Relationships in Adolescence. Annual Review of Sociology. 2003; 29:252-81.

Gladwell, Malcolm. The Tipping Point. Boston: Little, Brown; 2000.

Goffman, Erving. Asylums: Essays on the Social Situation of Mental Patients and Other Inmates. Garden City, NY: Anchor Books; 1961.

Gould, Madelyn S. Suicide and the Media. In: Hendin, H.; Mann, JJ., editors. Suicide Prevention: Clinical and Scientific Aspects. New York: New York Academy of Science; 2001. p. 200-24. 
Gould, Madelyn S.; Wallenstein, Sylvan; Davidson, Lucy. Suicide Clusters: A Critical Review. Suicide and Life Threatening Behavior. 1989; 19:17-29. [PubMed: 2652386]

Gould, Madelyn S.; Wallenstein, Sylvan; Kleinman, Marjorie; O’Carroll, Patrick; Mercy, J. Suicide Clusters: An Examination of Age-Specific Effects. American Journal of Public Health. 1990; 80:211-12. [PubMed: 2297071]

Gould, Madelyn S.; Kleinman, Marjorie; Lake, Alison M.; Forman, Judith; Midle, Jennifer Bassett. Newspaper Coverage of Suicide and Initiation of Suicide Clusters in Teenagers in the USA, 198896: A Retrospective, Population-Based, Case-Control Study. Lancet Psychiatry. 2014. http:// dx.doi.org/10.1016/S2215-0366(14)70225-1

Gray, R. Goethe: A Critical Introduction. Cambridge: Cambridge Press; 1967.

Harris, Kathleen Mullan. The National Longitudinal Study of Adolescent Health (Add Health), Waves I \& II, 1994-1996; Wave III, 2001-2002; Wave IV, 2007-2009 [machine-readable data file and documentation]. Chapel Hill, NC: Carolina Population Center, University of North Carolina at Chapel Hill; 2009.

Harris, Kathleen Mullan; Halpern, CT.; Whitsel, E.; Hussey, J.; Tabor, J.; Entzel, P.; Udry, JR. The National Longitudinal Study of Adolescent Health: Research Design. Chapel Hill, NC: Carolina Population Center, University of North Carolina at Chapel Hill; 2009. WWW DocumentRetrieved June 20, 2013 (http://www.cpc.unc.edu/projects/addhealth/design)

Hatfield, Elaine; Cacioppo, JT.; Rapson, RL. Emotional Contagion. New York: Cambridge University Press; 1994.

Haw, Camilla; Hawton, Keith; Niedzwiedz, Claire; Platt, Steve. Suicide Clusters: A Review of Risk Factors. Suicide and Life-Threatening Behavior. 2012; 43(1):97-108. [PubMed: 23356785]

Hedström, Peter; Liu, Ka-Yuet; Nordvik, Monica K. Interaction Domains and Suicide: A PopulationBased Panel Study of Suicides in Stockholm, 1991-1999. Social Forces. 2008; 87(2):713-40.

Hochschild, Arlie. The Managed Heart: Commercialization of Human Feeling. Berkeley: University of California Press; 1983.

Howes MJ, Hokanson JE, Loewenstein DA. Induction of depressive affect after prolonged exposure to a mildly depressed individual. Journal of personality and social psychology. 1985; 49(4):1110 1113. [PubMed: 4057047]

Hufford, Michael R. Alcohol and Suicidal Behavior. Clinical Psychology Review. 2001; 21(5):797_ 811. [PubMed: 11434231]

Larson, Reed W.; Almeida, David M. Emotional Transmission in the Daily Lives of Families: A New Paradigm for Studying Family Process. Journal of Marriage and Family. 1999; 61(1):5-20.

Lawler, Edward J. The Affect Theory of Social Exchange. In: Burke, Peter J., editor. Contemporary Social Psychological Theories. Stanford: Stanford University Press; 2006. p. 248-67.

Lin, Nan. Social Capital: A Theory of Social Structure and Action. Cambridge: Cambridge University Press; 2002.

Linn-Gust, Michelle; Cerel, Julie. Seeking Hope: Stories of the Suicide Bereaved. Albuquerque, NM: Chellehead Works; 2011.

Liu, Ruth X. Vulnerability to Friends' Suicide Influence: The Moderating Effects of Gender and Adolescent Depression. Journal of Youth and Adolescence. 2006; 35(3):479-89.

McCarthy, John D.; Hoge, Dean R. Analysis of Age Effects in Longitudinal Studies of Adolescent Self-Esteem. Developmental Psychology. 1982; 18(3):372-79.

McPherson, Miller; Smith-Lovin, Lynn; Cook, James M. Birds of a Feather: Homophily in Social Networks. Annual Review of Sociology. 2001; 27(2001):415-44.

Niederkrotenthaler, Thomas; Roderus, Brigitta; Alexanderson, Kristina; Rasmussen, Finn; Mittendorfer-Rutz, Ellenor. Exposure to Parental Mortality and Markers of Morbidity, and the Risks of Attempted and Completed Suicide in Offspring: An Analysis of Sensitive Life Periods. Journal of Epidemiology and Community Health. 2012; 66:232-9.

Niedzwiedz, Claire; Haw, Camilla; Hawton, Keith; Platt, Stephan. The Definition and Epidemiology of Clusters of Suicidal Behavior: A Systematic Review. Suicide and Life- Threatening Behavior. 2014; 44:1-11. [PubMed: 24313594] 
Pescosolido, Bernice A. Of Pride and Prejudice: The Role of Sociology and Social Networks in Integrating the Health Sciences. Journal of Health and Social Behavior. 2006; 47(3):189-208. [PubMed: 17066772]

Pescosolido, Bernice A.; Georgianna, Sharon. Durkheim, Suicide, and Religion: Toward a Network Theory of Suicide. American Sociological Review. 1989; 54(1):33-48. [PubMed: 11616426]

Phillips, David P. The Influence of Suggestion on Suicide: Substantive and Theoretical Implications of the Werther Effect. American Sociological Review. 1974; 39:340-54.

Recommendations for Reporting on Suicide. 2013. Retrieved on June 20 th 2013 (http:// reportingonsuicide.org/Recommendations2012.pdf)

Romer, Daniel; Jamieson, Patrick E.; Jamieson, Kathleen H. Are News Reports of Suicide Contagious? A Stringent Test in Six U.S. Cities. Journal of Communication. 2006; 56:253-70.

Royston, Patrick. Multiple Imputation of Missing Values: Further Update of Ice, with an Emphasis on Categorical Variables. Stata Journal. 2009; 9(3):466-77.

Schaefer, David R.; Kornienko, Olga; Fox, Andrew M. Misery Does Not Love Company: Network Selection Mechanisms and Depression Homophily. American Sociological Review. 2011; 76(5): 764-85.10.1177/0003122411420813

Schmidtke, Armin; Hafner, H. The Werther Effect After Television Films: New Evidence for an Old Hypothesis. Psychological Medicine. 1988; 18:665-76. [PubMed: 3263660]

Shadish, William R.; Campbell, Donald T.; Thomas, D. Experimental and Quasi-Experimental Designs for Generalized Causal Inference. New York Cook, NY: Houghton Mifflin; 2002.

Simmons, Roberta; Rosenberg, Florence; Rosenberg, Morris. Disturbance in the Self-Image at Adolescence. American Sociological Review. 1973; 38:553-68. [PubMed: 4745629]

Smith, Kirsten P.; Christakis, Nicholas A. Social Networks and Health. Annual Review of Sociology. 2008; 34(1):405-429.

Spirito, Anthony; Esposito-Smythers, Christianne. Attempted and Completed Suicide in Adolescence. Annual Review of Clinical Psychology. 2006; 2(1):237-266.

Stack, Steven. Celebrities and Suicide: A Taxonomy and Analysis, 1948-1983. American Sociological Review. 1987; 52(3):401-12. [PubMed: 11613886]

Stack, Steven. Suicide: A 15-Year Review of the Sociological Literature Part 1: Cultural and Economic Factors. Suicide and Life Threatening Behavior. 2000; 30(2):145-62. [PubMed: 10888055]

Stack, Steven. Suicide in the Media: A Quantitative Review of Studies Based on Nonfictional Stories. Suicide and Life-Threatening Behaviors. 2005; 35(2): 121-133.

Stack, Steven. Copycat Effects on Fictional Suicide: A Meta-Analysis. In: Stack, Steven; Lester, David, editors. Suicide and the Creative Arts. New York: Nova Science Publishers; 2009. p. 231-44.

Steinberg, Laurence; Graham, Sandra; O’Brien, Lia; Woolard, Jennifer; Cauffman, Elizabeth; Banich, Marie. Age Differences in Future Orientation and Delay Discounting. Child Development. 2009; 80(1):28-44. [PubMed: 19236391]

Stryker, Sheldon. Symbolic Interactionism: A Social Structural Version. Menlo Park, CA: The Benjamin Cummings Publishing Company; 1980.

Summers-Effler, Erika. The Micro Potential for Social Change: Emotion, Consciousness, and Social Movement. Sociological Theory. 2002; 20(1):41-60.

Summers-Effler, Erika. Defensive Strategies: The Formation and Social Implications of Patterened Self-Destructive Behavior. Advances in Group Processes. 2004; 21:309-25.

Taiminen, Tero; Salmenpera, Tuuli; Lehtinen, Klaus. A Suicide Epidemic in a Psychiatric Hospital. Suicide and Life-Threatening Behavior. 1992; 22(3):350-63. [PubMed: 1440749]

Tarde, Gabriel. The Laws of Imitation. New York: Henry Holt; 1903.

Thomeer, Mieke Beth; Umberson, Debra; Pudrovska, Tetyana. Marital Processes around Depression: A Gendered and Relational Perspective. Society and Mental Health. 2013; 3(3):151-169. [PubMed: 25914855]

Tishler, Carl C. Adolescent Suicide Attempts. Suicide and Life-Threatening Behavior. 1981; 11:8692. [PubMed: 7256821] 
Turner, Jonathan H. Human Emotions: A Sociological Theory. New York: Routledge; 2007.

Umberson, Debra; Williams, Kristi; Powers, Daniel A.; Liu, Hui; Needham, Belinda. You Make Me Sick: Marital Quality and Health Over the Life Course. Journal of Health and Social Behavior. 2006; 47(1):1-16. [PubMed: 16583772]

Umberson, Debra; Crosnoe, Robert; Reczek, Corinne. Social Relationships and Health Behavior Across the Life Course. Annual Review of Sociology. 2010; 36:139-57.

Umberson, Debra; Montez, Jennifer Karas. Social Relationships and Health: A Flashpoint for Health Policy. Journal of Health and Social Behavior. 2010; 51(1 suppl):S54-S66. [PubMed: 20943583]

Walls, Melissa L.; Chapple, Constance L.; Johnson, Kurt D. Strain, Emotion, and Suicide Among American Indian Youth. Deviant Behavior. 2007; 28(3):219-46.

Wasserman, Ira. Imitation and Suicide: A Reexamination of the Werther Effect. American Sociological Review. 1984; 49(3):427-36.

Williams, Kristi. Has the Future of Marriage Arrived? A Contemporary Examination of Gender, Marriage, and Psychological Well-Being. Journal of Health and Social Behavior. 2003; 44(4):470487. [PubMed: 15038144]

Wojnar, Marcin; Ilgen, Mark A.; Wojnar, Julita; McCammon, Ryan J.; Valenstein, Marcia; Brower, Kirk J. Sleep problems and suicidality in the National Comorbidity Survey Replication. Journal of Psychiatric Research. 2009; 43(5):526-531. [PubMed: 18778837]

Wong, Maria M.; Brower, Kirk J. The prospective relationship between sleep problems and suicidal behavior in the National Longitudinal Study of Adolescent Health. Journal of Psychiatric Research. 2012; 46(7):953-959. [PubMed: 22551658]

Wray, Matt; Colen, Cynthia; Pescosolido, Bernice A. The Sociology of Suicide. Annual Review of Sociology. 2011; 37:505-28.

\section{Biographies}

Anna S. Mueller is Assistant Professor of Sociology at the University of Memphis. Broadly, her research examines how social relationships may promote or harm adolescent health and wellbeing, with a focus on suicidality and obesity. Mueller's publications can be read in the American Sociological Review, American Journal of Sociology, and the Journal of Health and Social Behavior.

Seth Abrutyn is Assistant Professor of Sociology at the University of Memphis. As a general sociological theorist, his interests include sociocultural evolution, institutions, religion, social psychology, and emotions. In essence, his work emphasizes synthesizing disparate theories in order to make more robust and comprehensive theoretical principles. This larger project has culminated in several journal articles and, recently, a book titled Revisiting Institutionalism in Sociology. In addition to his more general concerns, he has recently become engaged in theoretical and empirical work aimed at extending and reformulating Durkheim's work on suicide; papers of which have appeared in American Sociological Review, Sociological Forum, and, soon, in Sociological Theory.

Cynthia Stockton earned her MA in sociology from the University of Memphis in 2013 and currently works as an instructor in the Department of Sociology at the University of Memphis. Her research investigates adolescent suicide and body weight. 
Table 1

Weighted Descriptive Statistics

\begin{tabular}{|c|c|c|}
\hline & Mean or Proportion & Standard Deviation \\
\hline \multicolumn{3}{|l|}{ Dependent Variables } \\
\hline Suicide Ideation (W4) & 0.067 & \\
\hline Suicide Attempt (W4) & 0.008 & \\
\hline \multicolumn{3}{|l|}{ Independent Variables } \\
\hline Role Model Suicide Attempt (W3) & 0.095 & \\
\hline Role Model Suicide Attempt (W4) & 0.064 & \\
\hline Suicide Attempt (W1) & 0.038 & \\
\hline Suicide Ideation (No Attempts) (W1) & 0.096 & \\
\hline Childhood Emotional Abuse (y/n) & 0.465 & \\
\hline Childhood Physical Abuse (y/n) & 0.168 & \\
\hline Childhood Sexual Abuse (y/n) & 0.046 & \\
\hline Diagnosed Depression (y/n) & 0.195 & \\
\hline Alcohol Abuse/Dependence (y/n) & 0.260 & \\
\hline Sleep Problems (y/n) & 0.115 & \\
\hline Married & 0.416 & \\
\hline Cohabiting & 0.122 & \\
\hline Divorced & 0.097 & \\
\hline Single (Ref) & 0.365 & \\
\hline Has Children (y/n) & 0.463 & \\
\hline Very Happy with Current Romantic Partner & 0.578 & \\
\hline Not Happy with Current Romantic Partner & 0.048 & \\
\hline Closeness to Romantic Partner & 4.456 & 2.607 \\
\hline Closeness to Parents & 4.525 & 0.924 \\
\hline Intact Family of Origin (W1) & 0.578 & \\
\hline Religious Attendance & 1.544 & 1.539 \\
\hline Female (W1) & 0.516 & \\
\hline Age (W1) & 15.882 & 1.748 \\
\hline African American (W1) & 0.147 & \\
\hline Asian or Asian American (W1) & 0.037 & \\
\hline Latina/o (W1) & 0.113 & \\
\hline Other Race or Ethnicity (W1) & 0.030 & \\
\hline White (Reference Group) & 0.673 & \\
\hline Parents' Education Level (W1) & 4.451 & 1.683 \\
\hline Socioeconomic Status & 5.037 & 1.685 \\
\hline Gay, Lesbian or Bisexual Identity & 0.034 & \\
\hline Unemployed (y/n) & 0.069 & \\
\hline Served in the Military $(\mathrm{y} / \mathrm{n})$ & 0.058 & \\
\hline Educational Attainment & & \\
\hline No Degree & 0.075 & \\
\hline
\end{tabular}




\begin{tabular}{|l|c|c|}
\hline & Mean or Proportion & Standard Deviation \\
\hline High School Degree & 0.163 & \\
Some College & 0.428 & \\
Bachelor's Degree (or higher) (Ref) & 0.333 & \\
\hline $\mathrm{N}$ & \multicolumn{2}{|c|}{10852} \\
\hline
\end{tabular}

Source: The National Longitudinal Study of Adolescent Health

Note: All variables measured at Wave IV unless otherwise noted. 


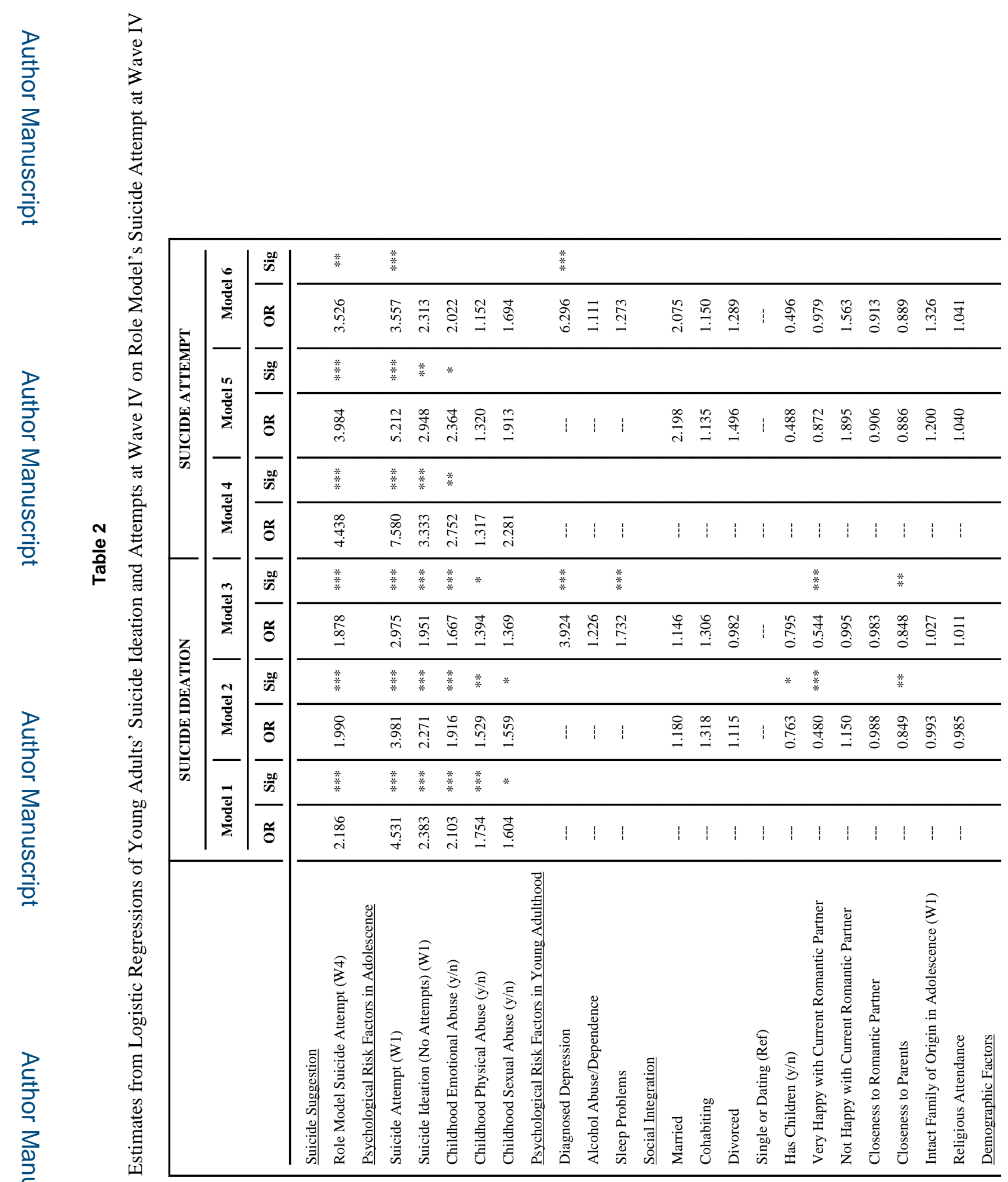

Sociol Perspect. Author manuscript; available in PMC 2016 June 01. 


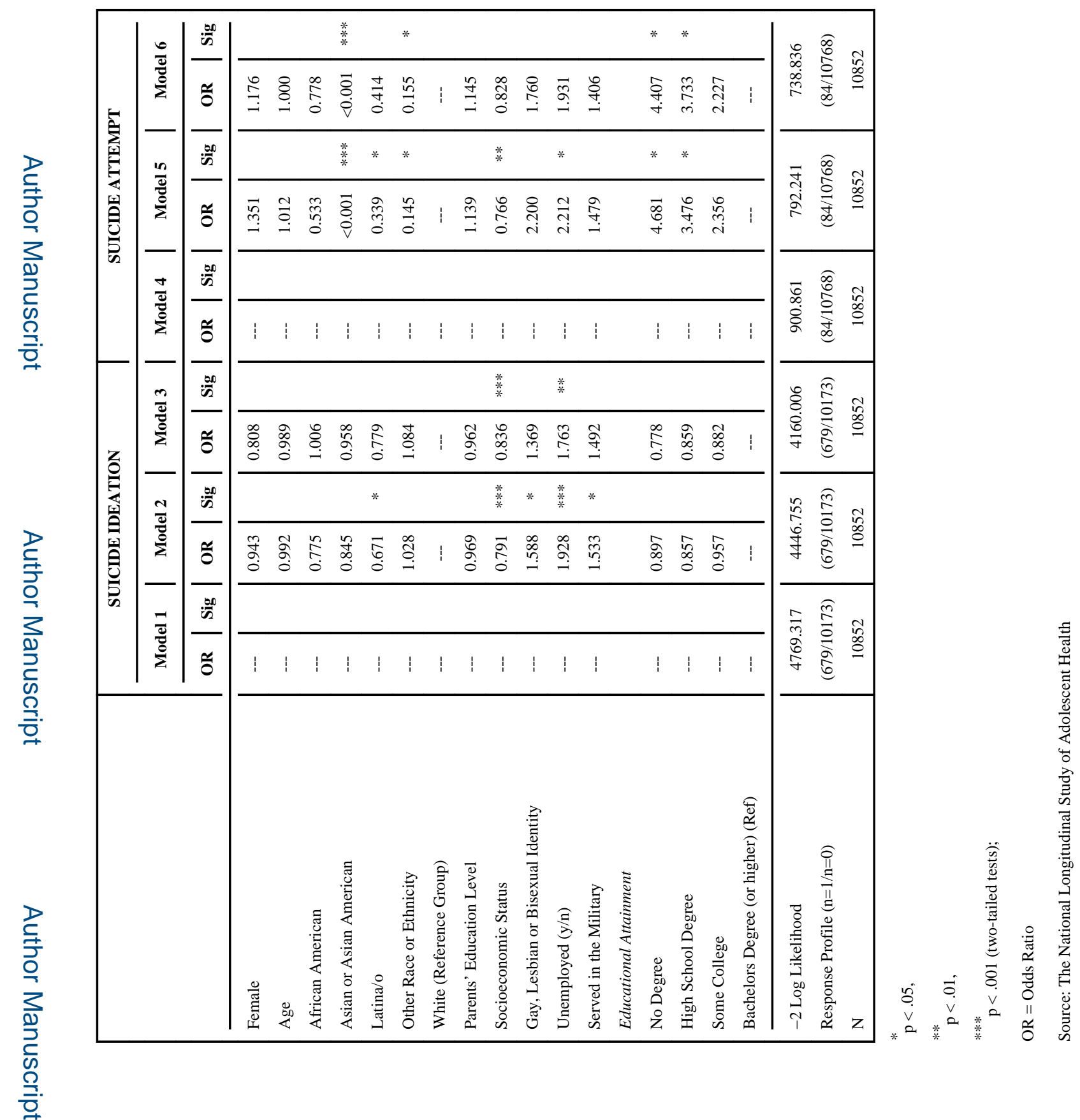

Sociol Perspect. Author manuscript; available in PMC 2016 June 01. 


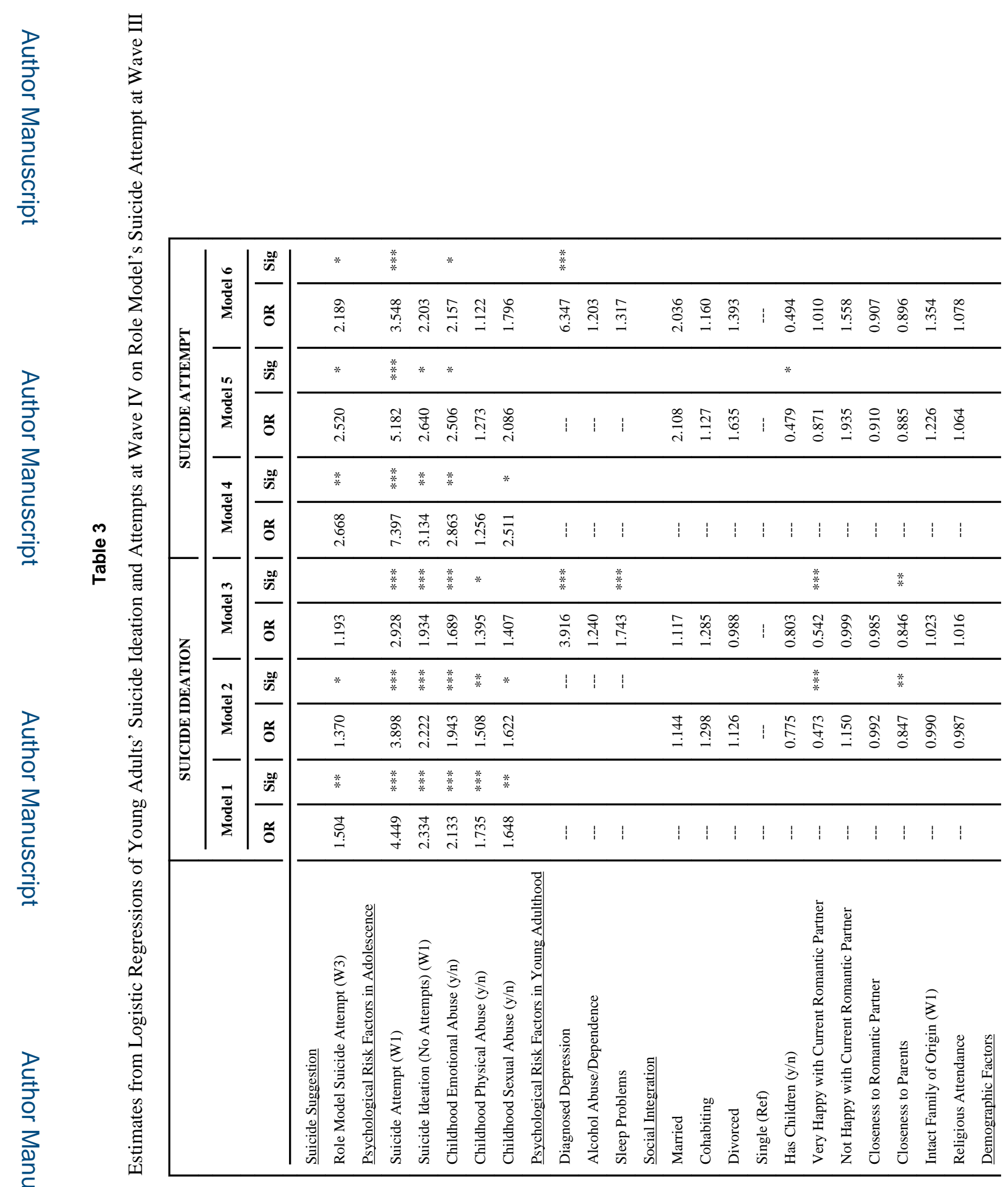

Sociol Perspect. Author manuscript; available in PMC 2016 June 01. 


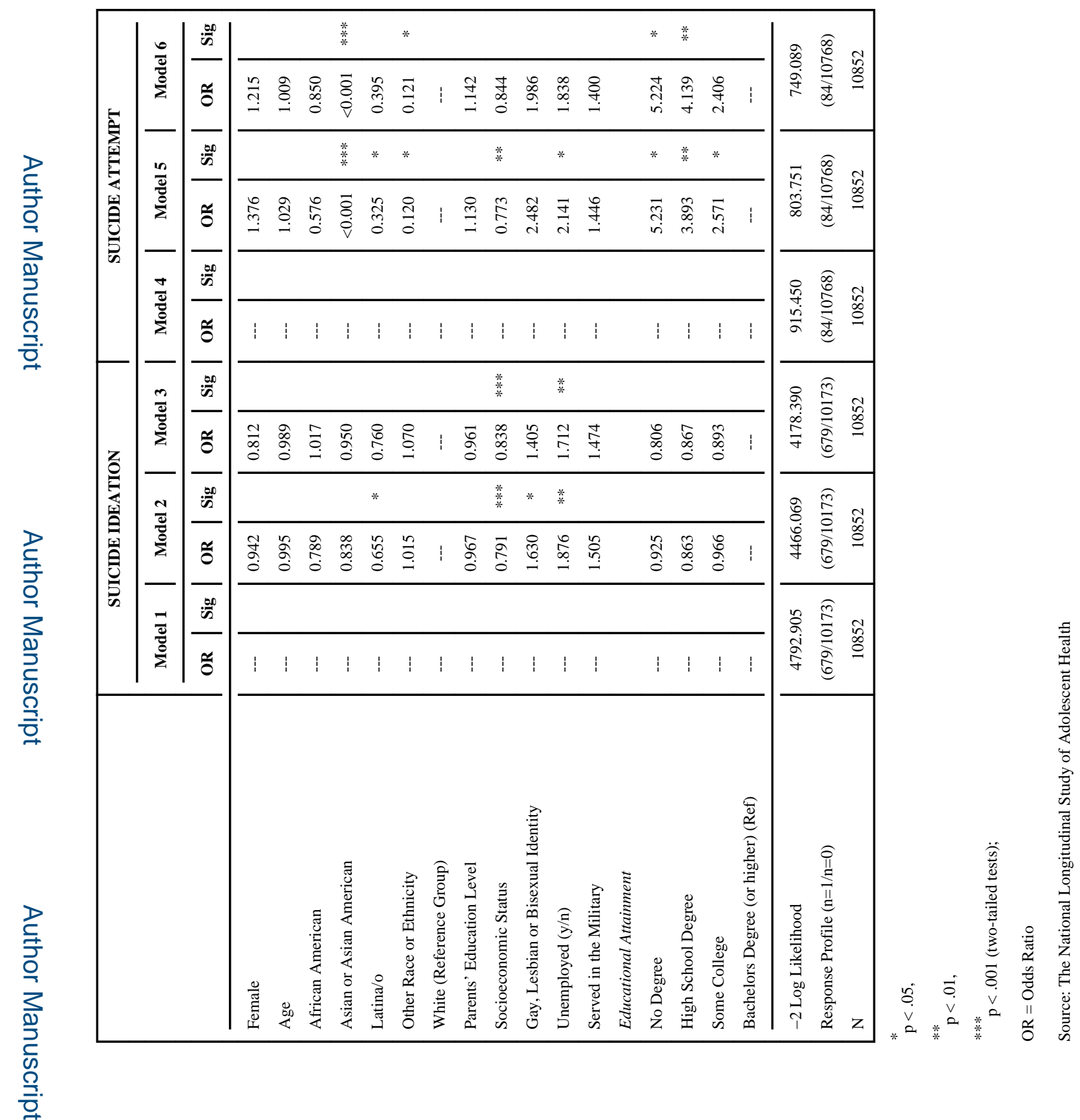

Sociol Perspect. Author manuscript; available in PMC 2016 June 01. 